November - 2007

\title{
Access to Communication for Deaf, Hard-of- Hearing and ESL Students in Blended Learning Courses
}

\author{
Gary L. Long \\ National Technical Institute for the Deaf \\ Rochester Institute of Technology, USA \\ Karen Vignare \\ Michigan State University, USA \\ Raychel P. Rappold \\ Online Learning \\ Rochester Institute of Technology, USA \\ Jim Mallory \\ National Technical Institute for the Deaf \\ Rochester Institute of Technology, USA
}

\begin{abstract}
In an effort to better understand student perceptions of communication in blended (online and traditional) learning courses, a 22 item questionnaire was developed and sent to all students registered for these courses at a large technology-focused college during three quarters of instruction. The respondents were divided into four groups: 1) hearing, 2) deaf, 3) hard-of-hearing $(\mathrm{D} / \mathrm{HH})$, and 3) English as a second language (ESL). Their perceptions of communication and the blended learning experience were examined. While the hearing and ESL students were positive about blended learning, the findings indicated that deaf and hard-of-hearing students reported that both the quality and quantity of their interactions with the professor and other students was greatly improved by the inclusion of an online component. ESL and hearing students were also positive about the blended experience; but the greatest benefit to communication access was observed by students with a hearing loss.
\end{abstract}

Keywords: Blended learning; deaf and hard-of-hearing students; online learning; learning community; cooperative learning

\section{Introduction}

Deaf students' struggles with reading, writing, and communication in the classroom have been well documented by many researchers over the past 20 years (Long \& Beil, 2005; Antia, Reed, \& 
Kreimeyer, 2005; Mallory \& Long, 2002; Johnson \& Johnson, 1986; Karchmer \& Mitchell, 2003). The need exists for technologies that will help deaf students to interact directly with their hearing peers. As Dansereau (1988) found in a program of research on cooperative learning, interaction and communication with peers, instructors, and experts produce the quickest, longest lasting and most transferable learning outcomes. Deaf and hard-of-hearing (D/HH) students in mainstream classes currently use the assistance of a third party, either a sign language interpreter or a voice-to-print 'captionist' to facilitate communication with hearing instructors and peers. While helping to provide access to the information, these systems are seen as lacking the clarity and immediacy of direct one-to-one communication (Long \& Beil, 2005; Foster, Long, \& Snell, 1999). With the advent of distance learning technology, email, instant messaging and discussion boards, there is now the opportunity for deaf and hard-of-hearing students to interact directly with their hearing peers and instructors without the message going through a third party. The present study examined student interactions and satisfaction with instructional delivery in blended learning courses where online communication is incorporated into traditional lecture classes.

\section{In-Class versus Online Learning}

When deaf and hard-of-hearing learners attend traditional in-class instruction, they typically do so with the assistance of sign language interpreters. However, the transfer of information from hearing instructors (who do not know sign language) through interpreters is a major concern to deaf and hard-of-hearing students. Long and Beil (2005) found that deaf adults in traditional learning environments often feel left out of classroom communication. Because of the lag that exists between the delivery of the information by the instructor and the signing of the content by the interpreter, deaf and hard-of-hearing learners report difficulty responding to the instructor's questions or asking a timely question. They feel out of sync with the instruction and, if the classroom pace is fairly quick, they do not feel comfortable stopping the flow to ask a question of clarification. In a study of main-streamed college students, Foster, Long and Snell, (1999) found that deaf and hard-of-hearing students often feel isolated or left out of the interactions that occur with other students and the instructor in the classroom.

In contrast to traditional lecture classes, online learning provides discussion boards, chat rooms, and other opportunities for both synchronous and asynchronous discussions related to the topic at hand. Inclusion of the online format slows the synchronous pace and allows the deaf, hard-ofhearing, and ESL students, more time to compose a response or ask a relevant question. Blended learning is a combination of traditional live classroom activities and online activities. Blended learning aims to join the best of classroom teaching and learning with the best of online teaching and learning. Interest in blended learning is growing as more universities become accustomed to using a courseware management system, and as academic leaders increasingly endorse active cooperative learning and the effective use of instructional technology. Some educational researchers see blended learning as a 'transformative' process for the university (Garrison \& Kanuka, 2004). The Rochester Institute of Technology (RIT) Online Learning instructional model defines a blended course as any course in which approximately 25 percent to 50 percent of classroom lectures and other seat time are replaced by instructor-guided online learning activities such as virtual team projects, synchronous chat sessions, and asynchronous discussions (Humbert \& Vignare, 2004). Blended learning courses that use online technologies to enable collaboration should improve quality and quantity of interaction between faculty and students, and students and students (Shea, Pickett, \& Pelz, 2003). 


\section{Review of the Literature}

The deaf and hard-of-hearing students enrolled in college face a multitude of barriers to inclusion in the classroom (Stinson \& Liu, 1999). In the online classroom however, the barriers tend to be lower and primarily focus on whether the student has the intellectual capability to participate (Mallory \& Long, 2003; 2002). It is important to build an understanding of the issues surrounding accessibility for $\mathrm{D} / \mathrm{HH}$ students, especially those focused around the use and spread of educational technologies.

Many legal and ethical discussions have taken place since the late 1980s on regulatory rules and standards required by legislation. Norm Coombs (as cited in Schmetzke, 2001) provides us with reasons why educators should be proactive in meeting the needs of students with disabilities.

First, ethically speaking, it simply is the right thing to do. Second, it is the economically sensible thing to do-considering the extra cost involved in producing alternative versions of instructional materials. Third, it is the selfish thing to do: With advancing age, as our senses grow weaker and our mobility decreases, we all stand a good chance of becoming beneficiaries of a barrier-free information infrastructure. (\$ 8)

While there is no doubt that it is good policy to provide a barrier-free classroom, the issues of accessibility often fail to include inclusive classroom communication (Schenker \& Scadden, 2002). One of the pedagogical strengths of online learning is the ability to provide a barrier-free or more level playing field for all students in the classroom (Harasim, Hiltz, Teles, \& Turroff, 1995). This environment, where communications are open to all - faculty to students and students to students - is conducive to deaf, hard-of-hearing, and English as a second language (ESL) students. In the traditional classroom, all communication is triangulated through the interpreter or others (Lang, 2002). Deaf students often feel they are behind the classroom dialogue and often do not wish to ask questions or interject thoughts (Long \& Beil, 2005). In online asynchronous learning environment, traditional classroom communication barriers are minimized (Richardson, Long, \& Woodley, 2003). While online learning presents opportunities to lower communication barriers for $\mathrm{D} / \mathrm{HH}$ and ESL students, most traditional-aged students who attend a residential university expect to attend classes in a classroom (Lang, 2002). The expectation of classroom attendance includes the D/HH students (Lang, 2002). The opportunity to meld the two learning environments presents itself through the blended learning format.

The online learning environment can help build a community of learners who cooperatively share ideas, knowledge, and opinions. Learning theory prominently recognizes the value of learning communities and the importance of cooperative learning for long-term retention of information (Dansereau, 1988; Phillips \& Soltis, 2004). While no doubt the traditional classroom is a learning community where cooperative learning can occur, it is clear that it is difficult to engage all learners in the community during a discussion. Stinson and Liu (1999) found that the development of a learning community was problematic for D/HH students.

Recent discussion has emphasized the importance of deep meaningful learning that is associated with hypothesis construction, problem solving, and conceptual organization, in contrast to memorization and retention of facts (Iran-Nejad, 1990; Pintrich, Marx, \& Boyle, 1993). While this kind of learning can occur in individual seatwork, it is more likely to take place in group activities. Often, the inability of $\mathrm{D} / \mathrm{HH}$ and hearing students to communicate easily and directly makes group participation difficult for the $\mathrm{D} / \mathrm{HH}$ member, even with an interpreter. 
Research by Long and Beil (2005, p. 6) has found that if communication breaks down, students are "less likely to become engaged, active learners," and the exchange of ideas is limited. In a study of US and Thai ESL students studying information technology and collaborating on a group project, Sarker (2005) found that both the US and the Thai students perceived more learning and information were transmitted by the US members of the team, even though capability and experience levels were equal. Sarker suggests this resulted from a communication/ language barrier, because the language medium was English. Although the Thai members of the team could potentially have contributed to the whole team's learning, it was perceived by both sides that they did not contribute in proportion to their potential. Even the Thai team members felt they had not been able to make a substantial contribution to the team's learning outcomes. Sarker stated that it is possible the Thai team members experienced frustration with the language barrier and could not share their knowledge effectively. In the same way, deaf students in a predominantly hearing setting and ESL students in an English environment may experience similar feelings of not being able to contribute to the group's learning, even though they have knowledge they would like to share. This underscores the necessity of providing a method of communication wherein all group members feel they can express themselves and are able to clearly communicate their ideas to their peers and receive feedback.

Liu, Moore, Graham, and Lee (2003) reviewed 21 journals and 246 articles related to computer use in the ESL classroom. They found 70 research-based articles that focused on the use of computer technology to support second and foreign language learning, many of which addressed the use of computer-mediated communication in the classroom. Since deaf students' struggles with English reading and writing are akin to those of English language learners (Antia, et al., 2005), strategies proven by research to improve the writing and language use of English language learners may also be beneficial to deaf students. Liu and colleagues (2003) found that "computer mediated communication seems to promote meaningful human interaction that can foster the language learning process” (p. 252). Computer-mediated communication has also been found to reduce anxiety about writing and increase the perception of social integration (Bishop, Taylor, \& Froy, 2000; Hertz-Lazarowitz \& Bar-Natan, 2001). Thus online communication may provide secondary language development benefits as well as important social interaction benefits.

\section{Inclusive Classrooms at the Rochester Institute for Technology}

The National Technical Institute for the Deaf (NTID) is located at the Rochester Institute for Technology (RIT). NTID is a leading undergraduate college whose primary mission is to provide post-secondary education to students who are deaf or hard of hearing. All NTID students are allowed to enroll in RIT courses provided they have the academic skills to do so. RIT has a significant commitment to creating an inclusive learning environment. In the past these efforts have relied primarily on having classroom interpreters for professors who do not sign. More recent efforts have included technologies like C-Print, a real-time, voice-to-print captioning system that utilizes trained 'captionists' in the classroom. RIT has also been a pioneer in distance learning. All distance learning courses must meet standards that make the classroom accessible to D/HH students.

With over 16,000 students and just over 1,100 D/HH students enrolled, approximately 50 percent of the D/HH students are taking mainstreamed RIT classes during each quarter. At NTID, students' services include smaller classes, faculty who can sign American Sign Language without interpreters, and aides. Their transition to RIT courses while still supported with note takers, voice-to-print captionists, and/ or interpreters, can still be difficult for students. There is constant and continual service and education provided to faculty on how to integrate $\mathrm{D} / \mathrm{HH}$ learners into 
the classroom (see www.rit.edu/classact). RIT's commitment to support and recognize students with disabilities, especially D/HH students, extends to its distance learning courses as well. The Online Learning department makes it clear to distance faculty that all new course processes and new materials must be designed to be accessible. All audio and video material must be captioned, even when the video is streamed.

\section{Blended Learning Survey}

The first year (2003-2004), a blended learning pilot program was introduced at the Rochester Institute of Technology; no demographic questions were asked of student participants in year one, but the initial results of the students' satisfaction survey seemed to mirror data reported by Dziuban, Hartman, Moskal, Sorg, and Truman (2004) at the University of Central Florida. Course completion rates were just over 95 percent, and nearly 70 percent of the students said they liked blended learning. During in-depth interviews, faculty indicated that they felt energized by redesigning their courses for a blended learning format.

The second year survey (2004-2005) continued to ask many of the satisfaction Likert-type questions, but was expanded to investigate the perceptions of deaf, hard-of-hearing, and ESL students enrolled in blended learning courses. Since classroom communication has been a significant challenge for the deaf and hard-of-hearing students, we were focused on the ease of communication for these students with their hearing peers and instructors. Hearing student and ESL student reactions to the blended format were also examined.

\section{Method}

\section{Procedure}

A 22 item "Blended End of Course Survey" was designed by the authors to explore student perceptions of communication in the blended learning instructional format. The questionnaire consisted of 16 Likert items, two open-ended questions, and four demographic items. Details of each follow:

- Two types of Likert items were used in this study. The first asked students to rate their agreement with specific statements using this five-point scale: $(5=$ Strongly Agree, $4=$ Agree, 3 = Neutral, 2 = Disagree, $1=$ Strongly Disagree). Examples of these items include: "I learned more about my fellow students because part of this course was online", and "I interacted more with fellow students because part of this course was online.” The second type of Likert question asked students to compare their level of interaction in this blended course to more traditional courses that meet only in the classroom using this five-point scale: $(5=$ Increased, $4=$ Somewhat Increased, $3=$ No Difference, 2 = Somewhat Decreased, 1 = Decreased). Examples of these ratings include: "The amount of interaction with other students" and "The quality of your interaction with the professor.”

- Open-ended questions allowed participants to type in a response in response boxes following each item, in their own words. The two open-ended questions were: "If more courses were offered like this (ones that meet in the classroom and online) what changes would you recommend" and "What did you like best about this course?" 
- Finally, the survey asked students to provide demographic information about: student workload (full or part-time); hearing status (hearing, hard-of-hearing or deaf); level of program (graduate or undergraduate); and whether English is a second language (Yes or No).

The Blended End of Course Survey was sent to 1,713 students who were enrolled in blended learning courses at the Rochester Ins 'titute of Technology during one academic year (2004-2005). Clipboard, a system for design and delivery of questionnaires, was used for the set-up of the survey, and each student was sent a live link via email and asked to access the survey by selecting the link. Students who responded were entered into a draw for a US \$50 gift certificate at the campus bookstore. Nine hundred and eight $(n=908)$ students responded to the survey, yielding a response rate of 53 percent.

\section{Participants}

Approximately 68 percent of the respondents were male and 32 percent female. The vast majority (96\%) were full-time students, while 4 percent were enrolled part-time. Eighty-five percent of the respondents were enrolled in undergraduate programs, and 15 percent were in graduate school. Thirty-six $(n=36)$ of the respondents were deaf, 28 were hard-of-hearing and 84 hearing students indicated that English was their second language. The remaining 760 students constituted the (non ESL) hearing student group.

\section{Results}

The following section summarizes our findings related to: 'Communication with Peers,' 'Communication with Instructors,' and 'Overall Satisfaction' with the blended learning experience.

\section{Communication with Peers}

Of particular interest in this study is how students perceived the ease of communication with their fellow students. The following questions relate to peer interactions. The stated percentage is the total number of individuals who indicated that they either Agreed or Strongly Agreed with each statement.

Table 1. Peer Interactions Online

\begin{tabular}{lcccc}
\hline & Deaf & $\begin{array}{c}\text { Hard-of- } \\
\text { Hearing }\end{array}$ & ESL & Hearing \\
\hline $\begin{array}{l}\text { Ilearned more about my fellow students because part of } \\
\text { this class was online. }\end{array}$ & $73 \%$ & $52 \%$ & $36 \%$ & $30 \%$ \\
$\begin{array}{l}\text { I interacted more with other students because part of } \\
\text { this course being online. }\end{array}$ & $51 \%$ & $39 \%$ & $29 \%$ & $30 \%$ \\
\hline
\end{tabular}

Note: ESL and Hearing students were primarily neutral about their level of communication with peers.

In their responses to these items, deaf and hard-of-hearing students indicated that they interacted and learned more about their peers because of the online format of the course. The online format provided a mechanism for deaf and hard-of-hearing students to have direct communication with 
their hearing peers. The ESL students said that they learned more about their fellow students, but were similar to other hearing students in terms of the amount of interaction.

The following questions ask students to compare the online course to traditional lecture courses and rate the amount and quality of interaction with other students. The stated percentage is for the number of individuals who indicated that the amount and quality of interaction either Somewhat Increased or Increased with the blended learning courses.

Table 2. Amount and Quality of Increased Interaction with Peers

\begin{tabular}{lcccc}
\hline & Deaf & $\begin{array}{c}\text { Hard-of- } \\
\text { Hearing }\end{array}$ & ESL & Hearing \\
\hline The amount of your interaction with other students. & $61 \%$ & $61 \%$ & $41 \%$ & $38 \%$ \\
The quality of your interaction with other students. & $61 \%$ & $61 \%$ & $36 \%$ & $34 \%$ \\
\hline
\end{tabular}

Note: ESL and Hearing students were primarily neutral about their level of communication with peers.

The most striking finding in the above items is that the deaf and hard-of-hearing students report a significant increase in the amount and quality of the interaction with peers when the blended course is compared to more traditional in-class instruction. The ESL students are just a little more positive than hearing students about online communication with peers. But the deaf and hard-ofhearing students are very positive regarding the benefits of adding an online component to a course. The following quotes, taken from the open-ended questions, by the deaf and hard-ofhearing students help to clarify this benefit:

"I think the online discussion is the best [part of] this class."

"I like the discussion board and being able to say my opinion. I think it was much more easier for me to stand up for the Social Issues that were presented than in person."

"[I like] learning about other students who are in this class and their opinion and beliefs about the things we learn in class!”

"I liked how I was able to interact more with other students, especially the hearing."

“At least I get to read about other students' thoughts and opinions about the assigned readings and assignments. It allows room for learning and increased knowledge.”

"I learned lots of stuff from the students who are in my class."

"Neutrality and respect regardless of race and disability. Only respect you receive is from knowledge and opinions not based on your appearances.” 
Thus the deaf and hard-of-hearing students felt that the online portion of these courses added to the ease of communication with their peers. The online experiences increased opportunities for sharing their opinions and actively participating in cooperative, peer learning.

\section{Communication with Instructors}

The ease of communication between the instructor and the students in the course are examined in the following questions. The stated percentage is for the number of individuals who indicated that the amount and quality of the interactions with the instructor either Somewhat Increased or Increased with this online course.

Table 3. Increased Communication with Instructor(s)

\begin{tabular}{lcccc}
\hline & Deaf & $\begin{array}{c}\text { Hard-of- } \\
\text { Hearing }\end{array}$ & ESL & Hearing \\
\hline The amount of your interaction with the professor. & $67 \%$ & $35 \%$ & $35 \%$ & $29 \%$ \\
& & & & \\
The quality of your interaction with the professor. & $67 \%$ & $48 \%$ & $39 \%$ & $30 \%$ \\
\hline
\end{tabular}

Note: ESL and Hearing students were mostly neutral about their level of communication with Instructors.

Deaf students were the group that reported that the online format led to the greatest increase in interaction with their instructors when compared to traditional in-class instruction. In comparison, approximately one-third of the 'other' students reported increased interaction with the instructor, whereas two-thirds of the deaf students indicated that the online format led to increased interactions with the instructor.

Deaf and hard-of-hearing students were very positive about the quality of interaction with their instructors when online interaction is present. Sixty-seven percent of the deaf students and 48 percent of the hard-of-hearing students said that the quality of the interactions with the faculty improved in online courses. The ESL and hearing students reported similar perceptions, with 39 percent and 30 percent respectively saying that the online format increased the quality of interactions with their instructors. The following quotes from deaf and hard-of-hearing students clearly articulate their perspective on communication with the instructor and interaction with course content.

"Since no interpreters are [available for] night classes, it is more convenient for me to communicate with teacher and students online."

"I seemed to have a greater voice in lending my opinion and questions regarding the topics in which I have received a great amount of feedback.”

"There was better motivation to read the course materials as well as search for our own perceptions and feelings regarding certain topics and being able to write it all down where everyone had a place to say something about it.” 
"The study of cultural differences and applying it to my life was interesting, and the use of online postings was much more interactive for me."

"More availability with the instructor. . ."

While many students said there were communication advantages to having online access to the instructor, the majority of the deaf students said it increased the amount and quality of those interactions.

\section{Overall Satisfaction with the Blended Learning Experience}

While the prior sections of this paper focused on communication with instructors and peers, this section examines overall student satisfaction with the blended learning experience. The following questions relate to student satisfaction with the blended learning format. The stated percentage is the total number of individuals who either Agreed or Strongly Agreed with each statement.

Table 4. Overall Satisfaction

\begin{tabular}{|c|c|c|c|c|}
\hline & Deaf & $\begin{array}{l}\text { Hard-of- } \\
\text { Hearing }\end{array}$ & ESL & Hearing \\
\hline $\begin{array}{l}\text { I like having part of the course online and part of it in } \\
\text { the classroom. }\end{array}$ & $79 \%$ & $74 \%$ & $55 \%$ & $62 \%$ \\
\hline I like leaming from online activities. & $76 \%$ & $61 \%$ & $42 \%$ & $51 \%$ \\
\hline $\begin{array}{l}\text { Other students should have the opportunity to take a } \\
\text { class like this in the future. }\end{array}$ & $82 \%$ & $74 \%$ & $49 \%$ & $56 \%$ \\
\hline
\end{tabular}

Note: While ESL and Hearing students were positive about their level of satisfaction with blended leaming, their second choice by an overwhelming percent was neutral, not negative.

Overall student reaction to blended learning was very positive, with the majority of students saying that they liked having part of the course online and that they enjoyed learning from online activities. The deaf and hard-of-hearing students generated the most positive ratings, however. Between 60 and 80 percent of the deaf and hard-of-hearing students reported that they liked having part of the class online, they were able to learn from the online activities, and believed that other students should have the opportunity to take a blended learning course. The hearing students were slightly more positive about the online experience than were the ESL students; however, both groups reported to benefit from the experience. The following quotes focus on the perceived advantages of blended learning by deaf and hard-of-hearing students.

"I like the part where we can take part of the course in and out of the classroom."

"I would say that (it) is fun to do project but I (would) rather try online for credit because I live off campus and (am) sick of going to class to learn something new, I would like to get online and learn something new that mean time is gonna be flexible which is much better." 
"I have more time at home to think about the questions."

"I like the discussion board the best."

"The fact that the course was combined with online time really allowed me to manage my time better. It is always a long day for me, so it takes a lot of stress away for me to be able to not go to class every time."

"[There is] flexibility in when to meet for class and [how to use] my own time."

"I can say this course is more independent for the students."

Along with the benefits of communication ease, deaf and hard-of-hearing students point to the flexibility of the schedule and the sense of independence as important advantages of the blended learning format. Similar comments were made by the hearing and ESL students in this study.

\section{Conclusion}

Students at RIT were positive about courses that used a blended learning format. When subgroups of students were examined, the deaf and hard-of-hearing students were the most positive. In traditional classes, these students are faced with the challenge of peer and teacher interactions filtered through a third party, specifically an interpreter or captionist. Students with a hearing loss are sometimes concerned that the intervention of the third party in the communication process may in some way distort the message. At times they feel that what they are signing is not being accurately represented to their instructors and peers. At other times, they feel that the interpreter may not have the content knowledge or 'sign skills' needed to accurately convey the lecture contents. To the deaf and hard-of-hearing student in the classroom, there is always the concern that part of the message is being lost. When the message is interpreted, there is always the added challenge of the lag that occurs. When this lag occurs in the classroom, the deaf and hard-ofhearing students are always behind their hearing peers in reception of the message. This lag often leads to difficulty responding to the instructor's questions or reluctance to stop the class to ask a clarification question. Thus deaf and hard-of-hearing students, at times, are not actively engaged in communication in mainstream classes.

A limitation of the present study is that the communication preferences of deaf and hard-ofhearing participants were not identified. Some of the students may have relied on sign language for communication, while others used speech and lip reading. Student communication preference may be related to satisfaction with the online learning experience and should be included in subsequent research. However, in the present study, in both groups of students with hearing loss, those who saw themselves as 'deaf' and those who saw themselves as 'hard-of-hearing' reported a benefit to communication access with the inclusion of an online component in a course.

The results of this study indicate that the blended learning instructional format offers some appealing advantages for students with hearing loss. The addition of discussion boards and other online tools that facilitate written communication provide tools for deaf and hard-of-hearing students to interact directly with hearing instructors and peers. Often questions are posted and students are asked to share their answers or opinions based on their reading of course materials and personal experience. Because of the online format, students with a hearing loss do not need to go through a third party to respond and they have direct access to the thinking of their hearing peers. They also have more time to compose their response than they do in a traditional lecture 
class. This allows for the free sharing of opinions and ideas by students who are typically challenged to do so in a traditional class. Students also are able to process and learn from the ideas and opinions of their classmates and instructors without the information going through a third party. In some ways, providing an option for online communication helped level the playing field and allowed the deaf and hard-of-hearing students greater ease of communication with peers and instructors. This may be why over 75 percent of the students with hearing loss said that other students should have the opportunity to take a class like this in the future.

\section{References}

Antia, S., Reed, S., \& Kreimeyer, K. (2005). Written language of deaf and hard-of-hearing students in public schools. Journal of Deaf Studies and Deaf Education, 10 (3), 244-255.

Bishop, J. M., Taylor, L., \& Froy, F. (2000). Computer-mediated communication use by the deaf and hard-of-hearing. Kybernetes, 29(9/10), 1078-1086.

Dansereau, D. (1988). Cooperative Learning Strategies. In C. E. Weinstein, E. T. Goetz, \& P. A. Alexander (Eds.), Learning and Study Strategies: Issues in assessment, instruction and evaluation (pp. 103-129). San Diego, CA: Academic Press.

Dziuban, C., Hartman, J., Moskal, P., Sorg, S., \& Truman, B. (2004). Three ALN Modalities: An institutional perspective. In J. Bourne \& J. C. Moore (Eds.), Elements of Quality Online Education: Into the Mainstream (pp. 127-148). Needham, MA: Sloan Center for Online Education.

Foster, S., Long, G., \& Snell, K. (1999). Inclusive instruction and learning for deaf students in postsecondary education. Journal of Deaf Studies and Deaf Education, 4(3), 225-235.

Garrison, D. R., \& Kanuka, H. (2004). Blended Learning: Uncovering its transformative potential in higher education. The Internet and Higher Education, 7(2), 95-105.

Harasim, L., Hiltz, S. R., Teles, L. \& Turroff, M. (1995). Learning Networks: A field guide to teaching and learning online. Cambridge, MA: MIT Press.

Hertz-Lazarowitz, R., \& Bar-Natan, I. (2001). Writing development of Arab and Jewish students using Cooperative Learning (CL) and Computer-Mediated Communication (CMC). Computers \& Education, 39(1), 19-36.

Humbert, J., \& Vignare, K. (2004). RIT introduces blended learning - successfully! In J. C. Moore (Ed.), Elements of Quality Online Education: Engaging communities, wisdom from the Sloan Consortium, Volume 2 in the 'Wisdom Series.' Needham, MA: Sloan Center for Online Education.

Iran-Nejad, A. (1990). Active and dynamic self-regulation of learning processes. Review of Educational Research, 60 (4), 573-602.

Johnson, D., \& Johnson, R. (1986). Mainstreaming Hearing Impaired Students: The effect of effort in communicating on cooperation and interpersonal attraction. The Journal of Psychology, 119(1), 31-44. 
Karchmer, M., \& Mitchell, R. (2003). Demographic and achievement characteristics of deaf and hard-of-hearing students. In M. Marschark \& P. Spencer (Eds.), Oxford Handbook of Deaf Studies, Language and Education (pp. 21-37). New York: Oxford.

Lang, H. (2002). Higher education for deaf students: Research priorities for the new millennium. Journal of Deaf Education and Deaf Studies, 7 (4), 267-280.

Liu, M., Moore, Z., Graham, L., \& Lee, S. (2003). A Look at the Research on Computer-based Technology Use in Second Language Learning: A review of the literature from 1990-2000. Journal of Research on Technology in Education, 34(3), 250-273.

Long, G., \& Beil, D. (2005). The importance of direct communication during continuing education workshops for deaf and hard-of-hearing professionals. Journal of Postsecondary Education and Disability. 18(1), 5-11.

Mallory, J. R., \& Long, G. L. (2003). Learning preferences for deaf and hard of hearing remote, online learners. Paper presented at the Instructional Technology and Education of the Deaf Supporting Learners symposium, Rochester, NY. Retrieved October 24, 2007 from: http://www.rit.edu/ techsym/

Mallory, J., \& Long, G. (2002). Postsecondary Education Programs Network (PEPNet). Kansas City, MO. Retrieved October 24, 2007 from: http://sunsite.utk.edu/cod/pec/other.html

National Technical Institute for the Deaf (n.d.) Class Act homepage: Rochester Institute of Technology. Retrieved October 24, 2007 from: http://www.rit.edu/ classact/

Phillips, D. C., \& Soltis, J. F. (2004). Perspectives on learning (4th edition). New York: Teachers College Press.

Pintrich, C. J., Marx, R. W., \& Boyle, R. A. (1993). Beyond 'Cold' Conceptual Change: The role of motivational beliefs and classroom contextual factors in the process of conceptual change. Review of Educational Research, 63, 167-199.

Richardson, J., Long, G., \& Woodley, A. (2003). Academic engagement and perceptions of quality in distance education. Open Learning, 18(3), 223-244.

Sarker, S. (2005). Knowledge transfer and collaboration in distributed U.S.-Thai teams. Journal of Computer Mediated Communication, 10(4). Retrieved October 24, 2007 from: http://jcmc.indiana.edu/vol10/issue4/sarker.html

Schenker, K., \& Scadden, L. (2002). The design of accessible distance education environments that use collaborative learning. Journal of Information Technologies and Disabilities, 8 (1). Retrieved October 24, 2007 from: http://www.rit.edu/ easi/itd/itdv08n1/scadden.htm

Schmetzke, A. (2001). Online distance education - "Anytime, Anywhere” but not for everyone. Journal of Information Technology and Disabilities, 7 (2). Retrieved October 24, 2007 from: http://www.rit.edu/ easi/itd/itdv07n2/axel.htm 
Access to Communication for Deaf, Hard-of-Hearing and ESL Students in Blended Learning Courses Long, Vignare, Rappold \& Mallory

Shea, P., Pickett, A., \& Pelz, W. (2003). A follow up investigation of "teacher presence" in the SUNY Learning Network. Journal of Asynchronous Learning Networks, 7(2), 61-80.

Stinson, M., \& Liu, Y. (1999). Participation of deaf and hard-of-hearing students in classes with hearing students. Journal of Deaf Studies and Deaf Education, 4 (3), 190-202.

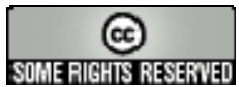

